\title{
ESTETIKA DAN ETIKA WUWUNGAN RUMAH TRADISIONAL JAWA DALAM ERA GLOBAL
}

\author{
Arif Suharson ${ }^{1}$ (arifkeramos@yahoo.com, Institut Seni Indonesia Yogyakarta)
}

\begin{abstract}
Philosophically, the ornamental art of wuwungan on top of Javanese traditional houses is characterized by such high Javanese esthetic and ethical values. It is necessary to re-actualize the existence and essence of the Javanese ornamental art of wuwungan in the era of industrial revolution 4.0. This cultural and traditional literacy will be necessary to strengthen the national characters and values in anticipation of the rapidly global era transformation. The new cultural values in the digital era are expected to ensure improvement of survival and establishment of new understandings inspired by local cultural diversity, appreciation, and knowledge to ensure the successful actualization of Javanese traditional cultural values. This is a qualitative study and accordingly this study will employ the qualitative method using the analytical interaction method through the grounded research. This study urges the re-actualization of understanding about Javanese philosophy in the form of the ornamental art of wuwungan in Javanese traditional houses that represents Javanese esthetic and ethical values. Javanese traditional local culture can serve as the local traditional identity and is a part of Indonesian national culture. Therefore, they have to be re-actualized and represented in the adjusted and adapted forms to meet the current condition of global. The technological advancement can serve as a smart tool to enhance the innovative and creative industry based on local cultures and global discourses.
\end{abstract}

Key Words: Wuwungan, Javanese Traditional House, Industrial Revolution, Global.

ABSTRAK

Seni hias wuwungan pada atap rumah tardisional Jawa memiliki karakteristik di dalamnya terkandung falsafah hidup orang Jawa dimana terdapat muatan ajaran luhur yang mantap dan mendalam menyangkut nilai estetika dan etika. Reaktualisasi terhadap eksistensi dan esensi seni hias wuwungan Jawa dibutuhkan. Hal ini dapat dijadikan sebagai literasi budaya tradisi menghadapi derasnya arus perubahan zaman yang serba cepat untuk memperkuat nilai-nilai karakter bangsa. Pengaruh-pengaruh budaya baru di era digital menjadi satu daya hidup untuk memberikan bentuk pemahaman baru atas inspirasi kekayaan budaya lokal, apresiasi, dan pengetahuan baru dalam mengaktualisasikan nilai-nilai ajaran luhur budaya Jawa secara luas. Penelitian ini akan memberikan penjelasan secara kualitatif, sehingga metode yang digunakan adalah metode kualitatif dengan menggunakan metode interaksi analisis melalui grounded research. Urgensi penelitian ini terkait dengan reaktualisasi pemahaman tentang filosofi hidup orang Jawa melalui seni ornamentasi wuwungan rumah tradisional Jawa dibalik wujud visual yang tampak berdasarkan korelasi Estetika dan Etika Jawa. Keunggulan budaya lokal Jawa sebagai identitas tradisi merupakan bagian budaya nasional Indonesia yang bernilai dapat diaktualisasikan kembali dalam representasi baru menyesuaikan dengan gerak perkembangan global. Kemajuan teknologi menjadi sarana cerdas untuk memajukan kreatifitas dalam peranannya memajukan industri kreatif yang inovatif berbasis tradisi budaya lokal dalam wacana global.

Kata Kunci: Wuwungan, Rumah Tradisional Jawa, Revolusi Industri, Global 


\section{PENDAHULUAN}

Tradisi budaya Jawa dalam membuat rumah selalu diikuti dengan hiasan kemuncak atau hiasan atap yang sering dikenal dengan istilah wuwungan. Wuwungan merupakan istilah lokal (Jawa) pengertiannya hampir sama dengan genteng, tetapi dipasang di atas molo pada pertemuan atap dengan atap. Untuk selanjutnya istilah wuwungan disamakan dengan bubungan (Ismunandar 1993, 88). Seni hias wuwungan merupakan bagian ornamentasi dalam elemen arsitektur atap rumah tradisional Jawa dan memiliki bentuk yang unik, sehingga visualisasi tersebut sangat menarik untuk dikaji secara ilmiah. Wuwungan pada atap rumah bukan hanya sebagai penghias semata, tetapi mempunyai makna simbol yang melekat pada budaya masyarakat Jawa. Hal ini karena pemilik rumah memberi isi pada bangunannya dengan makna-makna simbol tertentu yang mengandung kedalaman nilai-nilai ajaran luhur (filosofis), estetika dan etika Jawa yang mencerminkan jati dirinya. Hal lain yang perlu mendapatkan perhatian adalah keberadaan rumah tradisional Jawa dengan seni hias wuwungan mulai ditinggalkan masyarakat karena tuntutan kemajuan zaman yang menuntut perubahan.

Perkembangan

kebudayaan masyarakat Jawa yang saat ini sedang menuju ke arah masyarakat modern telah membawa dampak perubahan pada kebudayaan Jawa. Pandangan hidup dan sikap sebagian masyarakat Jawa mulai bergeser ke arah aspek yang cenderung berpola pikir rasional, mudah, cepat, dan serba instan. Masyarakat budaya Jawa seakan kurang percaya lagi pada keluhuran makna yang tersembunyi dibalik simbol-simbol. Banyak hasil budaya dari kesenian tradisi Jawa telah kehilangan daya simbolik yang berkaitan dengan ajaran luhur karena dianggap ngremit/jlimet, mistik, dan seni hias wuwungan dianggap ketinggalan zaman tidak sesuai dengan gaya trend disain rumah modern.

Seni hias wuwungan Jawa yang merupakan artefak sebagai pemenuhan kebutuhan rohani, bentuk dan ornamentasinya terikat dengan ajaran keagamaan, makna tersembunyi dibalik ragam hias tersebut karena terdapat pesan falsafah hidup melalui simbol-simbol (Haryono, 2008:100). Ragam hias memiliki fungsi menghiasi suatu objek, sehingga menambah keindahan dan nilai penghargaan baik spiritual maupun material. Di dalamya ditemukan nilainilai simbolik atau maksud-maksud tertentu yang ada hubungannya dengan pandangan hidup dari masyarakat penciptanya, mempunyai arti yang lebih bermakna disertai harapan-harapan tertentu (Gustami, 2008:4). Reaktualisasi ini juga berkaitan dengan perubahan global. Dimana telah terjadi perubahan pola pikir dan sudut pandang masyarakat Jawa tentang bagaimana membangun rumah yang sesuai dengan gaya hidup masyarakat modern. Konsep membuat rumah tersebut jangan sampai meninggalkan estetika dan etika ciri budaya lokal sebagai penanda kultural yang saling menguatkan keberadaan kebudayaan bangsa Indonesia. Hasil budaya Jawa dapat memberikan inspirasi dan alternatif dalam upaya membentengi diri dari pengaruh negatif budaya destruktif sekaligus menegakkan kepribadian bangsa.

Estetika seni hias wuwungan rumah tradisional Jawa yang diciptakan masyarakat Jawa diyakini terkait dengan nilai-nilai etika ajaran religius yang menjadi falsafah hidup bagi masyarakat budaya Jawa. Yang demikian sangat bebeda jauh dengan konsep masyarakat di era milenial, dimana akhir-akhir ini menunjukkan gejala sebaliknya seperti menghilangkan nilai estetik dan etika yang berhubungan dengan ajaran-ajaran luhur budaya Jawa. Rumah tidak hanya sebagai tempat tinggal tetapi disetiap sisinya memiliki 
nilai-nilai filosofi. Rumah tinggal Jawa sebagai sebuah lingkungan buatan, dalam hal ini adalah lingkungan dalam pengertian fisik, yaitu lingkungan alamiah yang disebut kosmos (Ronald, 2005:3). Kosmos juga diartikan sebagai ruang (spasial), sehingga bentukannya selalu bergantung pada siapa penghuninya dan kosmos dalam hal ini adalah kehidupan manusia yang selanjutnya dibedakan antara mikrokosmos dan makrokosmos (Mulder, D.C, 1970:24).

Produk kesenian yang dihasilkan dapat juga dipandang sebagai refleksi dari realitas yang terdapat di masyarakat. Sebagai bagian dari komunitas masyarakat, kriyawan pada umumnya dalam mengungkapkan sumber ide tidak terlepas dari berbagai pengaruh disekitarnya. Menginterpretasi sesuatu tidak lepas dari pengaruh hubungan sosial, sejarah, dan keakraban bahasa yang dimiliki (Finlay, 2009:6). Dalam keterkaitan berkarya, media menjadi material ekspresi untuk mengungkapkan bentuk ungkapan rasa, pikiran, gagasan, cita-cita fantasi dan lain-lain. Realitas objek seni itu menjadi sumber inspirasi lahirnya ide-ide dalam karya ciptanya, sehingga bentuk karya merupakan akumulasi ide yang membutuhkan sarana pengungkap (Marianto, 2011:23). Dengan demikian kehadiran karya kriya di era global harus mampu menghadirkan ide dan media terbarukan yang diselaraskan dengan kebutuhan refleksi realitas masyarakat terkini.

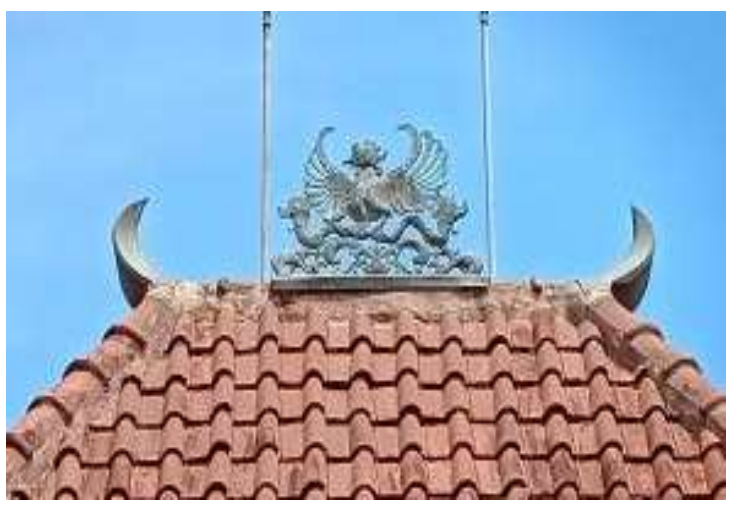

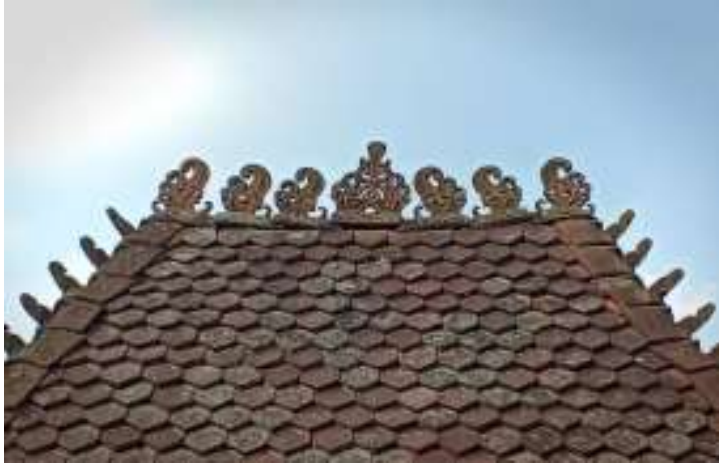

Gambar 1. Seni hias wuwungan pada atap rumah tradisional Jawa bermotif garudeya (pedalaman) dan bermotif gelung/sulur-suluran (pesisiran) (Foto: Suharson, 17 Desember 2018)

\section{METODE}

Penelitian ini berusaha mencari dan memberikan penjelasan secara kualitatif, sehingga metode yang digunakan adalah kualitatif. Melalui penelitian ini secara internal adalah sebagai salah satu telaah lingkup bidang ilmu seni rupa, khususnya seni kriya yang memanfaatkan material alam disekitar masyarakat budaya Jawa yaitu seni hias wuwungan pada rumah tradisional Jawa. Hal ini akan memiliki dampak yang berkelanjutan, sehingga kekayaan tradisi budaya Jawa akan tetap berjalan sebagai ciri local genius yang memperkaya khasanah budaya bangsa. Secara eksternal dapat dijadikan informasi dan referensi ornamentasi Jawa bagi para kriyawan akademis maupun non-akademis, serta sebagai sumbangan dalam usaha pelestarian seni budaya Indonesia di era global dalam memajukan industri kreatif berbasis tradisi budaya Jawa.

Pengumpulan data dalam penelitian ini dilakukan, baik secara langsung maupun tidak langsung terhadap sumber aslinya. Data yang dikumpulkan secara langsung dikelompokkan dalam data primer, sedangkan secara tidak langsung dikelompokkan dalam data sekunder. Untuk mendapatkan data penelitian yang akurat sesuai yang dibutuhkan, maka diperlukan metode pengumpulan data dengan tahap-tahap sebagai berikut: (1) Studi 
Pustaka (Library Research) melakukan metode pengumpulan data dokumentasi, buku-buku terbitan, jurnal/makalah ilmiah, literatur, manuskrip, penelitian-penelitian terdahulu, dan lain sebagainya; (2) Kajian Lapangan melakukan observasi, melihat, mencatat, dan memotret secara langsung; (3) Wawancara dengan model instrumen pedoman wawancara yang akan diajukan terhadap beberapa informan kunci dan kompeten. Wawancara dilakukan untuk mendapatkan data yang tidak diperoleh melalui studi pustaka dan observasi, maka dilakukan wawancara secara langsung dengan cara triangulasi data yaitu para pakar budayawan Jawa, para peneliti rumah adat Jawa, dan pengguna seni hias wuwungan rumah tradisional Jawa. Data dari nara sumber diolah dengan teknik Triangulasi sumber dan data untuk memperoleh data intersubjektif, sehingga diharapkan diperoleh konsep korelasi estetika dan etika pada seni hias wuwungan rumah tradisional Jawa yang valid.; (4) Analisis Data difokuskan pada bagian-bagian dan keseluruhan permasalahan terkait dengan penelitian ini. Analisis yang dilakukan dalam penelitian ini menggunakan analisis model interaktif. Analisis interaktif dengan pendekatan Grounded Research terdiri dari tiga alur kegiatan yang terjadi secara bersamaan yaitu, reduksi data, penyajian data, dan penarikan simpulan/verifikasi.

\section{PEMBAHASAN}

Kajian ini dilatarbelakangi oleh pola pemikiran masyarakat tradisional pada umumnya dan masyarakat Jawa pada khususnya yang hidup dalam lingkungan budaya estetika, etika, dan filosofi. Menurut Arya Ronald bahwa pada mulanya kehidupan manusia hanya terbatas pada kehidupannya sendiri. Setelah manusia mengembangkan nalar pemikirannya, maka kehidupan dirinya sendiri menjadi bagian dari kehidupan sekitarnya. Lingkup budaya Jawa ini disebut sebagai lingkup budaya kosmologi (Ronald $2005,19)$. Dalam lingkup pemikiran manusia yang terbatas, keberadaan dirinya di dalam keberadaan lingkungan disekitarnya seakanakan berada dalam lingkup batasan tertentu, yang tidak nyata (imajiner) namun dapat dirasakan bahkan disepakati keberadaannya.

Perubahan zaman yang hadir di tengah-tengah kehidupan berkesenian kita dimana semua berbasis pada data dan manajemen informasi haruslah disambut dengan keterbukaan pola pemikiran dan keterbukaan informasi. Hal ini menjadi dasar langkah kita mengikuti arus perubahan dan pergeseran tersebut untuk menentukan langkah bijak dan strategis agar karya kreatif seni kita terutama karya budaya tradisional tidak dianggap ketinggalan zaman. Menjalin hubungan dengan para kolega seni dari lintas disiplin keilmuan dapat menjadi sarana pertukaran informasi dan pemicu kreatif kita. Dari perjumpaan ini, akan kita temukan media-media dan altenatif kreatif seni yang dapat memberikan khasanah baru dalam proses karya cipta. Kreasi dan inovasi yang diciptakan tidak langsung meninggalkan esensi dari seni tradisi, tetapi memberikan penguatan kembali yang dihadirkan dalam wujud yang baru (novelty) (Suharson, 2018:21)

Karya seni hadir haruslah dapat berguna bagi masyarakat luas dan mampu menginspirasi banyak orang. Seperti yang disampaikan oleh Suwarno bahwa suatu pameran seni rupa, pementasan tari, atau teater, sebuah konser, tak lagi penting digelar dimana, apakah di suatu pojok desa Indonesia, di sebuah kota di Amerika, atau Eropa. Di dalam negeri atau di luar negeri, bukan lagi isu penting. Akan tetapi jauh lebih penting dan bermakna, jika mempersoalkan "isu" dan "isi"nya apa, produk pengetahuannya sepertii apa, 
apakah berdaya guna bagi orang banyak, memiliki dampak sosial-politik (social-politic impact) atau tidak, apakah menginspirasi orang lain, apakah mendorong menciptakan atmosfir akademik atau tidak, dan sejenisnya. Sejak saat itu mengingatkan kita semua bahwa seni hari ini memiliki multi fungsi, dari yang pragmatis, ekonomi, fungsi politik, sosial, bahkan fungsi "lintas iman". Fungsi lintas iman karena semestinya karya seni mampu menerobos sekat-sekat agama, keyakinan, suku, kelompok, dan ras. Seni atau karya seni semestinya tidak disempitkan untuk kepentingan-kepentingan sempit dan pragmatis semata (Wisetrotomo, 2018:12-13).

Berdasarkan informasi sumber dan data penelitian yang telah ditelaah menunjukkan bahwa, hasil karya seni tradisional di Indonesia terutama budaya Jawa, secara historis telah mampu membuktikan dirinya untuk menyesuaikan diri dalam perubahan zaman yang ada. Bahkan masyarakat Jawa yang terkenal memiliki sikap toleransi yang tinggi telah membuktikan mampu menerima dan mengadopsi akulturasi dari budaya lain. Walau demikian masyarakat Jawa tetap mempunyai posisi tawar kreatif yang handal, sehingga apa yang tampak sampai hari ini dalam berbagai hasil budaya terutama seni hias tetap memiliki ciri khas Jawa yang taat nilai-nilai estetika dan pranatapranata etika budaya Jawa. Tradisi turuntemurun pada hakikatnya meniru apa yang telah diwarisi secara turun-temurun (But Muchtar, 1991:3). Budaya masyarakat Jawa yang mewariskan seni hias wuwungan pada atap rumah Jawa ke generasi penerusnya untuk memantapkan tongkat estafet agar kekayaan budayanya tidak begitu saja hilang. Berbekal kreatifitas dan inovasi yang berkelanjutan, seni hias wuwungan pada atap rumah Jawa dihadirkan dalam berbagai desain kreatif selaras kebutuhan zamannya. Walau harus diakui terjadi degradasi nilai-nilai makna dalam pencapaian kreatifitas di era global seperti sekarang. Akan tetapi tetap terjalin hubungan erat akan nilai-nilai estetika dan etika sebagai wujud ekpresi pribadi dan komunal yang menggambarkan budaya Jawa yang kental dengan sistem kepercayaan pada keberadaan Tuhan Yang Maha Kuasa.

Peranan dunia digital dan akses informasi akan memberikan dampak secara signifikan dalam rangka reaktualisasi seni hias wuwungan pada bangunan rumah tradisional Jawa. Bahkan akan menjadi alternatif kolaborasi seni ornamentasi pada bangunan rumah-rumah masyarakat modern yang membutuhkan kesan indah, elegan, artistik, dan unik. Kehadiran rumah-rumah tradisional yang dimunculkan dalam bangunan-bangunan modern seperti hotel-hotel menambah nuansa etnik yang pada akhirnya menambah nuansa nyaman para tamu-tamu lain budaya. Hal ini dapat menjadi terobosan-terobosan kolaboratif yang dapat ditempuh agar eksistensi seni hias pada rumah tradisional khususnya Jawa dapat survive ditengah perubahan zaman modern. Tinggal bagaimana propaganda dari nilai-nilai esensi yang terkandung makna ajaran-ajaran luhur (filosofis) dimasukkan dalam rangka reaktualisasi yang dapat dipahami oleh seluruh lapisan masyarakat global.

Propaganda dalam hal ini dapat dimaksudkan sebagai reinterpretasi konsep rumah tradisional Jawa dengan seni hias wuwungan yang dihadirkan ditengah masyarakat dengan nuansa yang berbeda. Sehingga aktualisasinya dapat dicapai dengan memberikan pemahaman akan ajaran-ajaran filosofi budaya Jawa sebagai kekuatan karakter berbudi luhur masyarakat Indonesia. Juga dilakukan langkah-langkah nyata menghadirkan unsur-unsur rumah Jawa dengan seni hias wuwungan pada ranah publik sosial. Yaitu menempatkannya tidak hanya sebagai tempat tinggal atau hunian semata 
tetapi menjadi simbol estetik ikon suatu tempat publik yang berbeda. Akses informasi digital mengkaitkannya dengan iklan yang berhubungan dengan nilai-nilai tradisi yang unik dalam kehidupan global melalui publikasi di media sosial secara terencana, terstruktur, dan terprogram dengan baik.

Hal ini diyakini akan memberikan dampak nyata bagi reaktualiasi seni hias wuwungan pada rumah tradisional Jawa terkait dengan estetika dan etika dalam budaya Jawa. Aktualisasi konsep yang disesuaikan dengan kebutuhan masyarakat global akan menemukan jalur yang baik, kekhawatiran akan hilangnya nilai-nilai kearifan seni tradisi yang terdapat ajaranajaran luhur budaya Jawa dapat diminimalisir. Kehidupan budaya tradisional Jawa akan memberikan andil besar dalam ketahanan budaya dalam menghadapi budaya global seperti yang dijelaskan oleh Dharsono bahwa menghadapi global harus mampu menemukan jati-dirinya sendiri sebagai manusia Indonesia yakni: menggali, mengkaji dan mengolah potensi pluralitas budaya lokal sebagai modal agar mampu bersaing dalam percaturan global. Artinya untuk menghadapi global, maka harus studi lokal, semakin global akan semakin lokal. 1) revitalisasi nilai-nilai ajaran sebagai usaha untuk menemukan jatidirinya sebagai modal agar mampu bersaing dalam percaturan global. Maka ajaran tersebut perlu pelestarian secara preservasi maupun konservasi, sebagai bentuk ketahanan budaya, 2) Ajaran budaya tercermin lewat karya-karya seni klasik tradisional Jawa, perlu dilestarikan secara konservasi (pengembangan dan pemanfaatan nilai) sebagai kekayaan budaya, 3) Ajaran budaya merupakan modal yang mampu memberikan andil dalam revolusi moral bangsa, maka perlu disosialisasikan sebagai studi tentang ajaran budaya lokal, karena studi lokal akan mampu menghadapi global, dan semakin lokal akan semakin global (Kartika, 2016:213)

UNESCO sebagai wadah kebudayaan dunia menghimbau pada negara-negara anggota PBB untuk melakukan inventarisasi harta budaya dalam suatu bangsa yang disebabkan oleh kekhawatiran bahwa harta budaya dunia yang tak ternilai harganya akan menghilang satu persatu diganti dengan produk-produk budaya global yang tidak mengenal batas dan identitas. Penggalian kebudayaan lokal menjadi hal yang sangat penting sebagai salah satu gejala kecenderungan pengembangan pengetahuan pasca krisis multi dimensi. Kebudayaan yang menstradisi pada tiap-tiap daerah dipercaya memiliki kearifan yang dalam terhadap lingkungan serta nilai-nilai yang bersifat universal. Nilai-nilai tentang ke-Tuhanan serta nilai-nilai kemasyarakatan, baik masyarakat manusia atau masyarakat alam yang mulai terkubur ditinggalkan dan dilupakan karena imbas modernisasi.

Dewasa ini umat seluruh dunia sedang dilanda keguncangan luar biasa akibat proses globalisasi dengan kemajuan dalam bidang teknologi komunikasi. Pengaruh budaya dari Barat dalam proses globlalisai dialami oleh masyarakat dan negara-negara timur terutama Indonesia. Kebudayaan Barat bukan tipe kebudayaan yang mulus dan sempurna. Disamping unsur-unsur yang positif bagi pengembangan pemikiran dan bagi kemajuan kehidupan umat yang amat dibutuhkan bagi dunia Timur, ia juga mengandung dan menawarkan filsafat materialisme dan sekularisme dengan racikan racun yang amat membahayakan nilai-nilai budaya ketimuran yang menjunjung tinggi agama dan dan filsafat ketuhanan (Simuh, 2018:1-2). Hal ini memberi pemahaman bahwa bangsa Timur dalam hal ini Indonesia memiliki karakteristik filosofi tersebut yang banyak dihadirkan melalui hasil 
karya seni yang estetik dengan etika yang menyertainya.

Konsep filsafat yang menonjol, memberikan pemahaman tentang ilmu humaniora, khusunya estetika sastra dan budaya berkaitan dengan bahasa sebagai simbol di salah satu pihak, dan dengan hakikat karya sastra itu sendiri, yaitu sebagai kreativitas imajinatif di pihak yang lain. Estetika budaya, pertama jelas terkandung dalam karya sastra dan karya seni pada umumnya, sebagai dunia yang lain (heterocosmos), merupakan bagian integral kebudayaan. Kedua, seluruh aspek kebudayaan, baik dalam bentuk konkret maupun abstrak menampilkan ciri-ciri keindahan. Estetika, sastra, dan kebudayaan adalah aspek-aspek terpenting yang diperlukan oleh manusia dalam rangka mempertahankan keseimbangan antara dimensi jasmani dan rohani. Pada dasarnya manusia tidak bisa hidup tanpa keindahan ( Kutha Ratna, 2011:vi). Untuk itu, dasar di atas dapat menjadi pedoman dalam membaca estetika melalui karya seni yang indah terdapat pada bentuk seni hias wuwungan yang memiliki simbol dipahamkan melalui bahasa teks atau sastra agar dapat dimengerti oleh masyarakat secara luas sebagai hasil kebudayaan masyarakat itu sendiri, khususnya estetika dan etika Jawa melalui media digital.

Estetika dan etika wuwungan rumah tradisional Jawa yang terkait dengan nilai-nilai ajaran luhur budaya Jawa tidak boleh hilang dalam percaturan global. Dibutuhkan peran dari semua lini masyarakat budaya untuk mengaktualisasikan hal tersebut. Terdapat tiga komponen penting untuk menghidupkan kebudayaan di tengah-tengah masyarakat yaitu: aspek lembaga budaya, isi budaya, dan efek budaya (Williams, 1983: 17-19). Pemerintah melalui undang-undang cagar budaya nomor 11 tahun 2010 yang dikeluarkan oleh Presiden Republik Indonesia menyatakan bahwa, cagar budaya merupakan kekayaan budaya bangsa sebagai wujud pemikiran dan perilaku kehidupan manusia yang penting artinya bagi pemahaman dan pengembangan sejarah, ilmu pengetahuan, dan kebudayaan dalam kehidupan bermasyarakat, berbangsa, dan bernegara sehingga perlu dilestarikan dan dikelola secara tepat melalui upaya pelindungan, pengembangan, dan pemanfaatan dalam rangka memajukan kebudayaan nasional untuk sebesar-besarnya kemakmuran rakyat. Cagar budaya berupa benda, bangunan, struktur, situs, dan kawasan perlu dikelola oleh pemerintah dan pemerintah daerah dengan meningkatkan peran serta masyarakat untuk melindungi, mengembangkan, dan memanfaatkan cagar budaya.

Dengan adanya perubahan paradigma pelestarian cagar budaya, diperlukan keseimbangan aspek ideologis, akademis, ekologis, dan ekonomis guna meningkatkan kesejahteraan rakyat. Saling memberikan dukungan dan menguatkan, niscaya reaktualisasi estetika dan etika seni hias wuwungan pada rumah Jawa sebagai artefak ilmu, seni, dan asset budaya Indonesia dalam era global dapat diwujudkan pada kehidupan masyarakat modern. Sehingga bangsa Indonesia tetap menjadi bangsa yang dikenal memiliki ciri identitas berkarakter, berpribadi luhur, sopan, santun, dan ramah ditengah kehidupan masyarakat modern yang mencari identitas ideologi dengan kemajuan teknologi. 


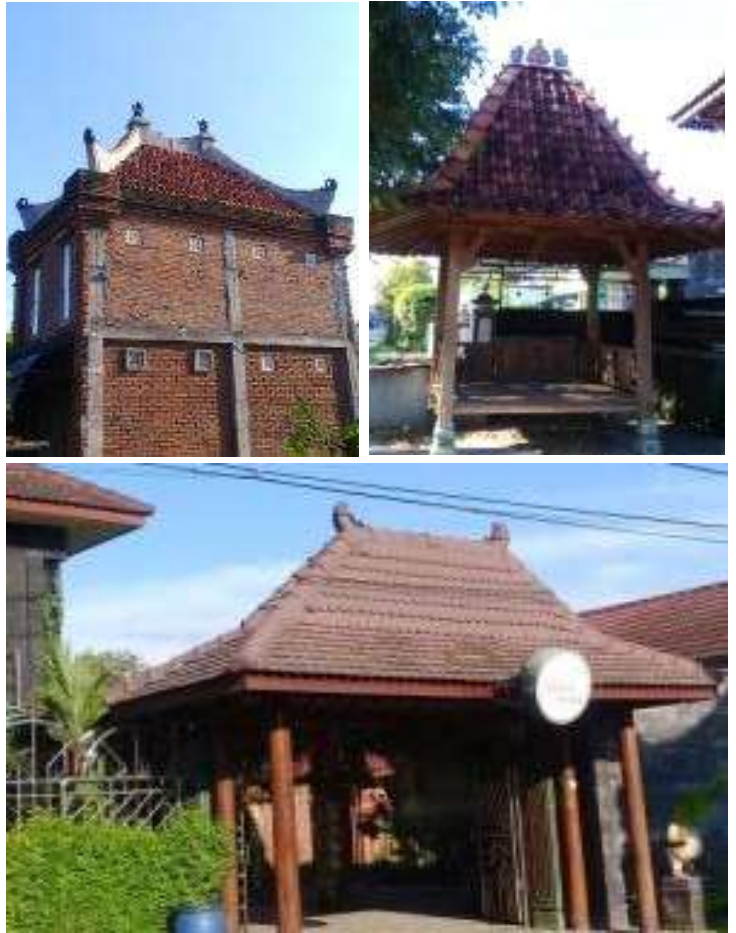

Gambar 2. Aktualisasi estetika seni hias wuwung pada rumah gaya modern sebagai gallery, pintu gerbang, dan gazebo. (Sumber: Dokumen foto penulis, 2017)

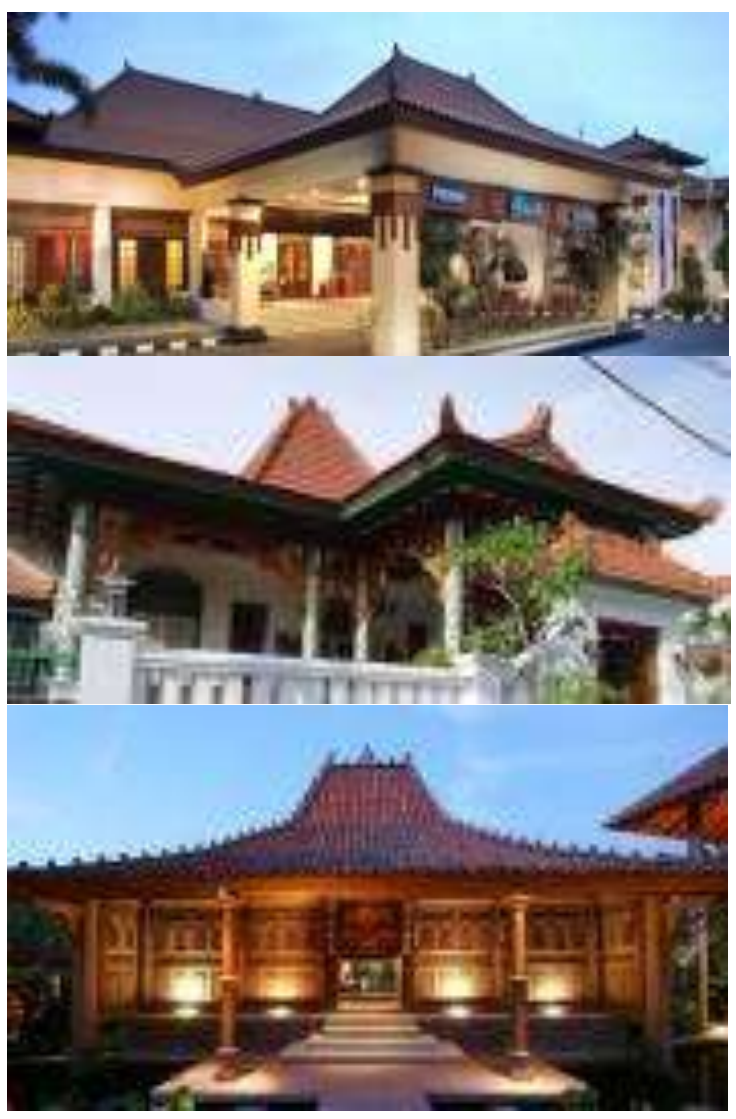

Gambar 3. Aktualisasi estetika seni hias wuwung pada hotel dan guest house (Sumber: Dokumen foto penulis, 2017)

\section{PENUTUP}

Masyarakat modern banyak yang memandang hasil karya seni yang merupakan produk masa lalu dianggap sebagai tradisi yang usang dan sudah habis bahkan mati. Pandangan masyarakat modern yang telah dimudahkan dengan teknologi informasi dan berhubungan dengan masyarakat global beranggapan tentang seni tradisi budaya Jawa dianggap kuno dan ketinggalan zaman. Walau pada kenyataannya tidak semua masyarakat modern beranggapan sama, yaitu melihat seni tradisi sebagai suatu karya seni yang tinggi dan adiluhung yang patut dilestarikan. Jika kita menyadari tentang hakikat seni tradisi budaya maka, seni tradisi Jawa yang dianggap kuno tersebut merupakan mata rantai kesinambungan masa lalu, masa kini, dan masa yang akan datang. Yang dapat dijadikan sumber data ilmiah seni tradisi dalam upaya pelestarain nilai-nilai estetika dan etika sekaligus sebagai identitas etnik budaya.

Eksistensi dan esensi seni hias wuwungan rumah Jawa memberikan andil besar terhadap ketahanan budaya tradisional. Dengan menggali potensi local genius, melakukan kajian secara ilmiah dan memberikan pemahaman yang baik kepada masyarakat secara luas. Maka, nilai-nilai filosofis ajaran luhur budaya Jawa akan mampu menjadi modal dasar pembangunan karakter pribadi masyarakat dalam menghadapi persaingan secara global. Nilainilai budaya ketimuran yang menjunjung tinggi agama dan filsafat ketuhanan dalam budaya Jawa harus tetap dipertahankan dalam kehidupan masyarakat global. Seni hias wuwungan rumah Jawa yang diciptakan masyarakat Jawa diyakini memiliki korelasi terhadap estetika dan etika yang memuliakan terkandung maksud tujuan dengan ajaran religiusnya yang menjadi falsafah hidup bagi masyarakat budaya Jawa. Hal ini sangat berbeda jauh dengan konsep masyarakat di 
era modern seperti sekarang. Dimana akhirakhir ini menunjukkan gejala sebaliknya seperti menghilangkan nilai-nilai luhur di atas.

Pola pikir masyarakat modern yang mengarah pada perubahan global tersebut turut pula merubah cara pandang terhadap lunturnya pemahaman ajaran-ajaran filosofis Jawa. Jika hal ini terus terjadi akan membuat perubahan yang besar dan menghilangkan ciri khas budaya lokal Jawa. Diyakini bahwa dalam ajaran-ajaran filosofis Jawa memiliki esensi yang sangat berguna bagi pembangunan karakter generasi mendatang, seperti yang terdapat pada seni hias wuwungan rumah Jawa Sehingga penggalian budaya yang yang bersumber dari kebudayaan lokal Jawa sangat penting untuk dilakukan.

\section{DAFTAR PUSTAKA}

Finlay, Linda. 2009, Debating Phenomenological Research Method dalam Journal Phenomology \& Practice, Volume 3, No.1, Open University.

Gustami, SP. 2007, Butir Butir Mutiara Estetika Timur: Ide Dasar Penciptaan Seni Kriya Indonesia, Prasista, Yogyakarta.

2008, Nukilan Seni Ornamen Indonesia, Diterbitkan Jurusan Kriya, Fakultas Seni Rupa, Yogyakarta.

Haryono, Timbul. 2008, Seni Pertunjukan dan Seni Rupa Dalam Perspektif Arkeologi Seni, ISI Press, Surakarta.

Kutha Ratna, Nyoman. 2011, Estetika Sastra, dan Budaya, Pustaka Pelajar, Yogyakarta.

Marianto, M. Dwi. 2011, Menempa Quanta Mengurai Seni, BP ISI Yogyakarta.

Mulder, D.C. 1970, Java Religie en Kunst: de Religie van Java, Amsterdam.
Mulder, Niels. 1992, Inside Southeast AsiaThai, Javanese, and Filipino, PT. Gramedia Jakarta.

Ronald, Arya. 2005, Nilai-Nilai Arsitektur Rumah Tradisional Jawa, Gadjah Mada University Press, Yogyakarta.

Simuh. 2018, Sufisme Jawa: Transformasi Tasawuf Islam ke Mistik Jawa, Yayasan Bentang Budaya, Yogyakarta.

Sony Kartika, Dharsono. 2016, Kreasi Artistik Perjumpaan Tradisi Modern Dalam Paradigma Kekaryaan Seni, Citra Seni Lembaga Pengkajian dan Konservasi Budaya Nusantara, Karanganyar.

Suharson, Arif. 2018, Ruang Baru Kriya Nusantara dalam Katalog Pameran Besar Seni Kriya UNDAGI\#2 Inspirasi Budaya Nusantara Dalam Kriya, Kementerian Pendidikan dan Kebudayaan Direktorat Jenderal Kebudayaan Direktorat Kesenian.

Suwarno, Wisetrotomo. 2018, Meniti Ombak Di Era Milenial (Problem Di Sekitar Fungsi Seni, dan Kritik Kebudayaan), Pidato IImiah, Pada Dies Natalis XXXIV ISI Yogyakarta, Yogyakarta .

Williams, Raymond. 1983, Culture, Glasgow William Collinds Sons, \& Co.Ltd., terjemahan angkatan (1999), Universitas Gajah Mada. Yogyakarta. 